\title{
Flow Measurement and Control in Gas Pipeline System using Intelligent Sonic Nozzle Sensor
}

\author{
Mouloud Guemana ${ }^{1}$, Slimane Aissani ${ }^{1}$ Ahmed Hafaifa ${ }^{2}$ \\ 1 Engineering Physics and Hydrocarbons Laboratory, \\ University of Boumerdes 35000 DZ, Algeria, \\ guemana_m@yahoo.fr,slim50dz@yahoo.fr. \\ 2 Advanced Automation and Industrial Diagnosis Laboratory, \\ Faculty of Science and Technology, \\ University of Djelfa 17000 DZ, Algeria, \\ Hafaifa@hotmail.com.
}

\begin{abstract}
In industrials sector, many engineering applications used the intelligent techniques to savings on maintenance costs. In this work, we discuss a new intelligent measurement technique of gas flow, in industrials compressions systems, using a sonic nozzle sensor, and we examine the performance of the calibration and measurement of gas flow used in the transport of high volume of natural gas pipeline system. We propose the development of this approach and we discuss the feasibility and validity of this intelligent sensor in real plant. This work demonstrates that sonic nozzles can be operated successfully as a prover for natural gas and for the critical flow in nozzles for unprocessed natural gas.
\end{abstract}

Keywords: Computer flow control, compression gas pipeline, counting gas, critical flow, gas flow measurement, sonic nozzle.

\section{Introduction}

The measurement of the fluids flows in industrial field is a very widespread measurement, in the oil sector, the production of oil and the invoicing of the produced quantities of oil is carried out on the knowledge of the flows of these liquids in drains which can reach two meters in diameter. In this sector, the results of measurements are used to establish an invoicing and enter the field of legal metrology. Indeed, the measurement of the flow of the fluids is a very important operation in any industrial activity. Its importance is dictated by the control and the regulation of the manufacturing process of the products, by the starting of the energy machines (engines, gas turbines, pumps etc.). Lastly, by the marketing of the energy fluids in the natural gas transactions, the importance of this sector is presented in the worldwide market, the worldwide market of the flowmeters was estimated at 2500 million dollars in 1995 [10], and is in constant increase [12]. The commercial transactions of the debitmetric measurements of gas and oil, they represent also an enormous sales turnover in these last years. Being given the size of these markets, it is surprising to note that the precision and the capacity of the majority of the flowmeters remain weak in comparison with the measuring instruments used for the other sizes (temperature, pressure). In this work we will expose the principle and the fundamental aspects of the flows of fluids in the industrial conduits and will try to determine of them the problems of measurement of the flow. We will be interested more particularly in the practical problem of the debitmetric, we will recall in what follows the definitions given in the certain principal terms suitable for the measurement of the gas flow. We purpose in this study to measure the mass flow rate of a compressible fluid through a convergent divergent nozzle with respect to inlet and outlet pressures. The gas flow meters must operate properly and reliably, because the picked up data constitute not only the basis for billing quantities of delivered gas, but also for the rational exploitation of the pipeline network. Nowadays, seen to the transported quantities of gas, the small errors of parameters measurement can have serious consequences [23].

This paper examines the performance of onsite calibration of sonic nozzle sensor in gas pipeline system. The regulation of the sonic nozzle sensor during the periodic checks, measuring instruments is compared to the standards in order to verify their performance; these calibrations are generally performed on site. For the gas pipeline system, an on site calibration is generally difficult to run because it requires to provide 
a headline to install standard meter and also to be able to impose rates flow corresponding to the points defined by the rules. In practice these sensor are calibrated in the workshop facilities which are approved by the competent authorities. Among this calibration, we can also use the venturi sonic nozzles [7].

\section{Sonic Nozzle Technology}

The sonic nozzle is fluid flow measurement devices used in a number of industrial applications [1, 4, 7, 11 and 17], is based on the principle that gas flow accelerates to critical velocity at the nozzle throat. At critical velocity, the mass flow-rate of gas flowing through the nozzle is the maximum possible for the existing upstream conditions [13]. Because it has no mobile parts it is very stable, stress-resistant, and can be used repeatedly, with very low maintenance, due to their high repeatability and reproducibility, they are considered to be very precise. Sonic devices operate on the principle that as fluid flows through the meter; the fluid accelerates as it approaches the throat. As the differential pressure increases, the velocity at the throat increases. When the velocity of the fluid reaches the local speed of sound, it is considered choked, sonic or critical [14]. Once the flow has reached the critical state, increasing the differential pressure will not affect the fluid flow rate [20]. Several components are important to a sonic device metering system; upstream and downstream piping, pressure sensors, temperature sensors and flow computers [7, 15]. The tube of venturi is made up mainly by truncated cones joined together by their small base, thus forming a throttling. The narrowest part is called collar, this tube of venturi is shown in Figure 1. Its cost price is definitely higher than that of a diaphragm, opposite which it has in particular the advantage following: smaller loss of pressure, which can be advantageous for the important flows accompanied by pressures relatively low, necessary right lengths upstream and downstream smaller [1].

The sonic nozzle is similar to a subsonic variable head type flow meter in that a constriction is present in the flow stream [12]. As the gas flows through the converging section of the nozzle, the inlet pressure is converted to velocity, which reaches a maximum at the throat. When the fluid velocity reaches the speed of sound at the throat, the flow rate will vary linearly with the inlet pressure and will not be affected by downstream pressure fluctuations [13]. The pressure drop across the nozzle must be sufficient to maintain sonic flow at the throat. Normally, sonic flow occurs when the downstream pressure is not greater than onehalf the upstream pressure.

The principle of a flowmeter with differential pressure is based on a static disturbing system made up of a body of throttling which causes a fall of pressure whose value is function of the flow of the flow and the thermodynamic characteristics of the fluid to be measured. For a flow of fluid in a drain the equation of Bernoulli is written like continuation [1]: (I.3) While supposing constant, horizontal control, catches practically located at the same altitude, as it is shown on the Figure 2.

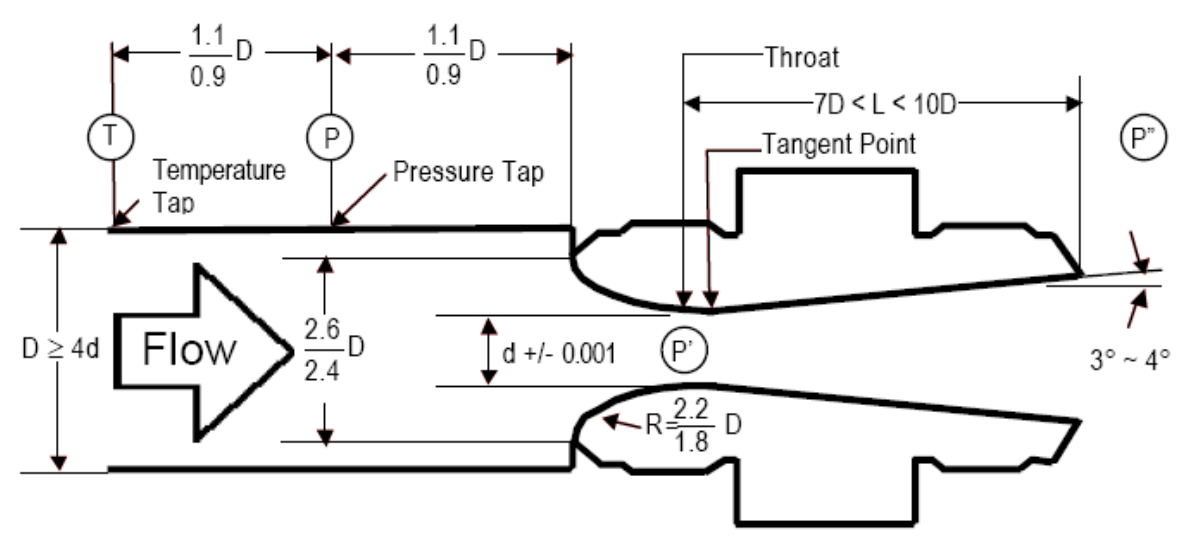

Figure 1. Measurement solutions type Venturi Nozzle 

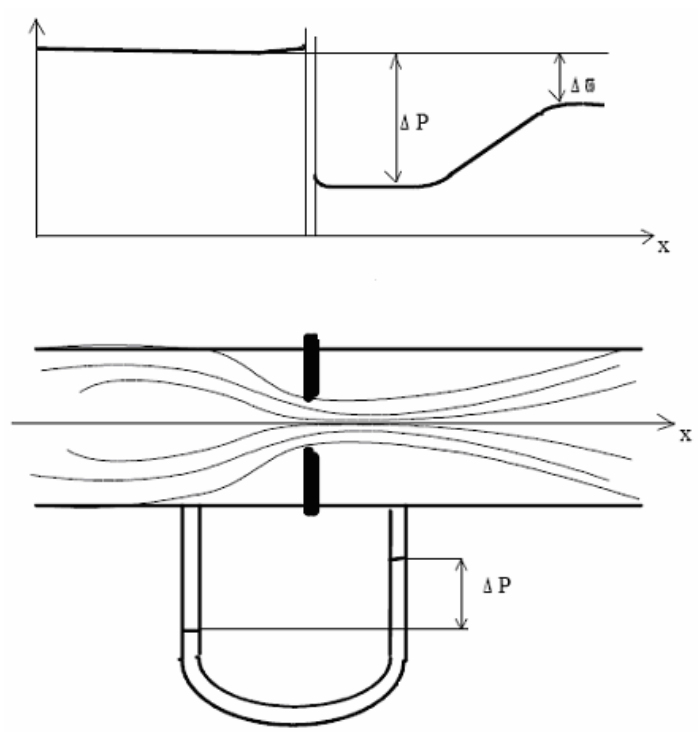

Figure 2. Flowmeter with differential pressure

One supposing that the flow is permanent, one dimensional, compressible and isentropic of an ideal gas in venturi nozzle, the general equations of fluid motion in a net current can be written:

- Differential equation of continuity:

$\frac{\partial \rho}{\rho}+\frac{\partial s}{s}+\frac{\partial u}{u}=0$

- Equation of dynamics:

$d\left(\frac{u^{2}}{2}\right)+\frac{d P}{\rho}=0$

- Equation of energy:

$d\left(\frac{u^{2}}{2}\right)+d(C p . T)=0$

- Equation of state of ideal gas:

$$
\frac{p}{\rho}=r T
$$

We note that for an ideal gas, the specific heat $C_{p}$ at the constant pressure is given by the relation:

$$
C p=\frac{\gamma \cdot r}{\gamma-1}
$$

Used some transformations of fluid we obtain the important relation of Hugoniot [1].

$$
\frac{d s}{s}+\frac{d u}{u}\left(1-M^{2}\right)=0
$$

Where, $\frac{u}{a}=M$ is the local Mach number [21].
The analysis of this equation relatively to the main sections of the nozzle gives us:

- In the convergent nozzle, we have $d s<0$, we obtain $d u>0$ and the speed increases, subsonic flow.

- At the neck ds $=0$ so :

$$
\frac{d u}{u}\left(1-M^{2}\right)=0
$$

Two cases may arise, either:

1. $\mathrm{dU}=0$ and the velocity reaches a maximum and then decreases

2. $\mathbf{M}^{2}=1$ and the velocity becomes sonic at the neck.

- Finally, in the divergent part was ds $>0$ in this case there are two outlets.

If $\mathrm{M}<1$ we will have $\mathrm{du}<0$ and the velocity decreases, subsonic flow, If $M>1$ we will have $d u>0$ speed continues to increase, supersonic flow.

The equation (7) therefore shows that in given piping where is sating an isentropic flow, the velocity of the fluid can not be equal to that the sound $(M=1)$ except at the neck of the venturi nozzle (In the section of piping where area has a maximum or minimum).

\section{Mass Flow Venturi Nozzle}

The mass flow venturi nozzle is passing through a slice of any kind, we have:

$Q=\rho . S . u$

To move a section of well-defined and constant to calculate the flow simply determine with good precision the values $\rho$ and $u$. By integrating the thermodynamic equation (3), we have the equation of Zeuner [1, 7]:

$\frac{u^{2}}{2}+h=C t e$

Similarly for an ideal gas, we have the following relation:

$h=\frac{\gamma}{\gamma-1} \frac{p}{\rho}$

And replacing in the above equation we get:

$\frac{u^{2}}{2}+\frac{\gamma}{\gamma-1} \frac{p}{\rho}=C t e$ 
The application of this equation for the upstream section in which $\mathrm{u}=0$ and any section of the nozzle, gives us:

$\frac{u^{2}}{2}+\frac{\gamma}{\gamma-1} \frac{p}{\rho}=\frac{\gamma}{\gamma-1} \frac{p_{a m}}{\rho_{a m}}$

Given that the flow is isentropic, we will have speed in a section equals:

$$
u=\sqrt{\frac{2 \gamma}{\gamma-1} \frac{p_{a m}}{\rho_{a m}}\left(1-\left(\frac{p}{p_{a m}}\right)^{\frac{\gamma-1}{\gamma}}\right)}
$$

This relation give the equations of fluid motion are often expressed in terms of Mach number, then the equation (13) can be written:

$$
1+\frac{\gamma-1}{2} M^{2}=\frac{T_{a m}}{T}=\left(\frac{p_{a m}}{p}\right)^{\frac{\gamma-1}{\gamma}}=\left(\frac{\rho_{a m}}{\rho}\right)^{\gamma-1}
$$

The equation (14) is very important; it allows the determination of critical parameters of the flow. And finally, by substituting $\mathrm{u}$ in the equation (12), we have:

$$
Q=\rho \cdot \sqrt{\frac{2 \gamma}{\gamma-1} \frac{p_{a m}}{\rho_{a m}}\left(1-\left(\frac{p}{p_{a m}}\right)^{\frac{\gamma-1}{\gamma}}\right)}
$$

Given that the flow is isentropic, we have:

$$
Q=\rho_{a m} S \sqrt{\frac{2 \gamma}{\gamma-1} \frac{p_{a m}}{\rho_{a m}}} \cdot\left(\frac{p}{p_{a m}}\right)^{\frac{1}{\gamma}} \cdot \sqrt{1-\left(\frac{p}{p_{a m}}\right)^{\frac{\gamma-1}{\gamma}}}
$$

By maintaining constant conditions generating, the mass flow is based on grouping $Y=f\left(\frac{P}{P_{a m}}\right)$.

\subsection{Critical flow}

From Equation (16), we see that maintaining constant upstream conditions implies that the flow depends only on the function:

$Y=W^{\frac{1}{\gamma}} \cdot \sqrt{1-W^{\frac{\gamma-1}{\gamma}}}$

In turn, this function depends only on $\left(\frac{p}{p_{a m}}=W\right)$ reaches a maximum when we have then: $\frac{p}{p_{a m}}=\frac{p_{c}}{p_{a m}}=\left(\frac{2}{\gamma+1}\right)^{\frac{\gamma}{\gamma-1}}$

This parameter is called the critical ratio of relaxation $\left(\mathrm{W}_{\mathrm{cr}}\right)$ and the corresponding speed to this ratio is equal to:

$u_{c}=\sqrt{\frac{2 \gamma}{\gamma-1} \frac{p_{a m}}{\rho_{a m}}}$

Substituting $p_{a m}, \rho_{a m}$ the values of dependent parameters collar, we have finally:

$u_{c}=\sqrt{\gamma \frac{p_{c}}{\rho_{c}}}$ Which is the speed of sound in the neck of the venturi nozzle and the mass flow will be:

$Q=S_{c} \sqrt{\frac{\gamma}{r}} \cdot\left(\frac{2}{\gamma+1}\right)^{\frac{\gamma+1}{2(\gamma-1)}} \cdot \frac{p_{a m}}{\sqrt{T_{a m}}}$

Denotes the relaxation coefficient magnitude $A=\sqrt{\frac{\gamma}{r}} \cdot\left(\frac{2}{\gamma+1}\right)^{\frac{\gamma+1}{2(\gamma-1)}}$ and we write:

$Q=S_{c} \cdot A \cdot \frac{p_{a m}}{\sqrt{T_{a m}}}$

We thus see that the mass flow of a sonic flow depends only on parameters upstream of venturi nozzle. This value represents a maximum possible flow nozzle.

For example, we give the characteristics of the critical state of a nozzle without a diverging natural gas $(\gamma=1,22)$.

$$
\begin{aligned}
& \frac{p_{c}}{p_{a m}}=\left(\frac{2}{\gamma+1}\right)^{\frac{\gamma}{\gamma-1}}=0,561 ; \frac{\rho_{c}}{\rho_{a m}}=\left(\frac{2}{\gamma+1}\right)^{\frac{1}{\gamma-1}}=0,622 ; \\
& \frac{T_{c}}{T_{a m}}=\frac{2}{\gamma+1}=0,901 ; \frac{a_{c}}{a_{a m}}=\left(\frac{2}{\gamma+1}\right)^{\frac{1}{2}}=0,949
\end{aligned}
$$

\section{Flow Computers}

Flow computers are electronic devices that can use various process measurements to calculate flow. Te flow computers have been utilised to solve various linearization and compensation equations that were previously done using other methods [6, 8, 9, 10 and 15]. They are especially convenient to operators who need stand alone devices to be configured to be able to add, subtract, 
multiply, divide, drop out, square root, linearize, totalize, solve for exponents, algorithms, etc.

In our application, the sonic nozzle in a gas compression system may be calibrated to measure accurately when it is operated at a particular pressure and temperature. The flow computers can make corrections for Reynolds number effects and changing fluid density, as well as remove non-linearity $[16,18]$. Because the gas can be compressed, measurement error will occur when the sonic nozzle is operated at a different pressure and temperature. When provided with the raw flow, operating pressure, and operating temperature measurements, a flow computer can be used to mathematically correct the raw flow measurement to account for real-time changes in operating pressure and temperature. The gas flow measurement and control in gas pipeline system using intelligent sonic nozzle sensor proposed in this paper is depicted in Figure 3.

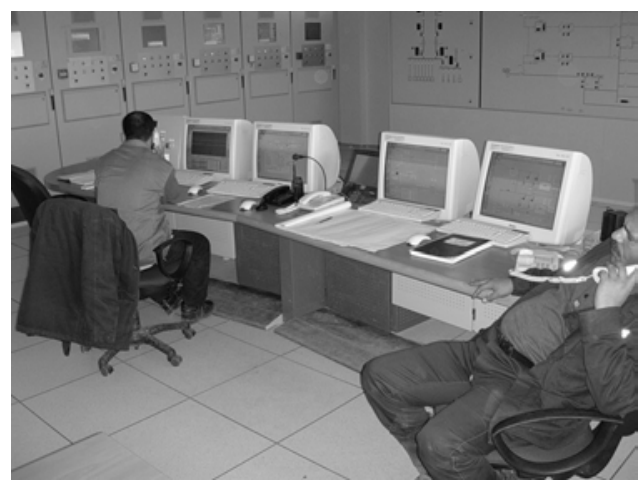

Figure 4. Computers used in gas flow measurement

According to a study presented in [19], the classification of the flowmeters installed in the world industry of gas shows that the flowmeters with diaphragm constitute total followed by the flowmeters harnesses with a rate of; Emergent technologies of the ultrasound and for vortex purpose start to gain ground in a progressive way. In Algeria, according to a study presented in [7], the principal stations of counting of hydrocarbons

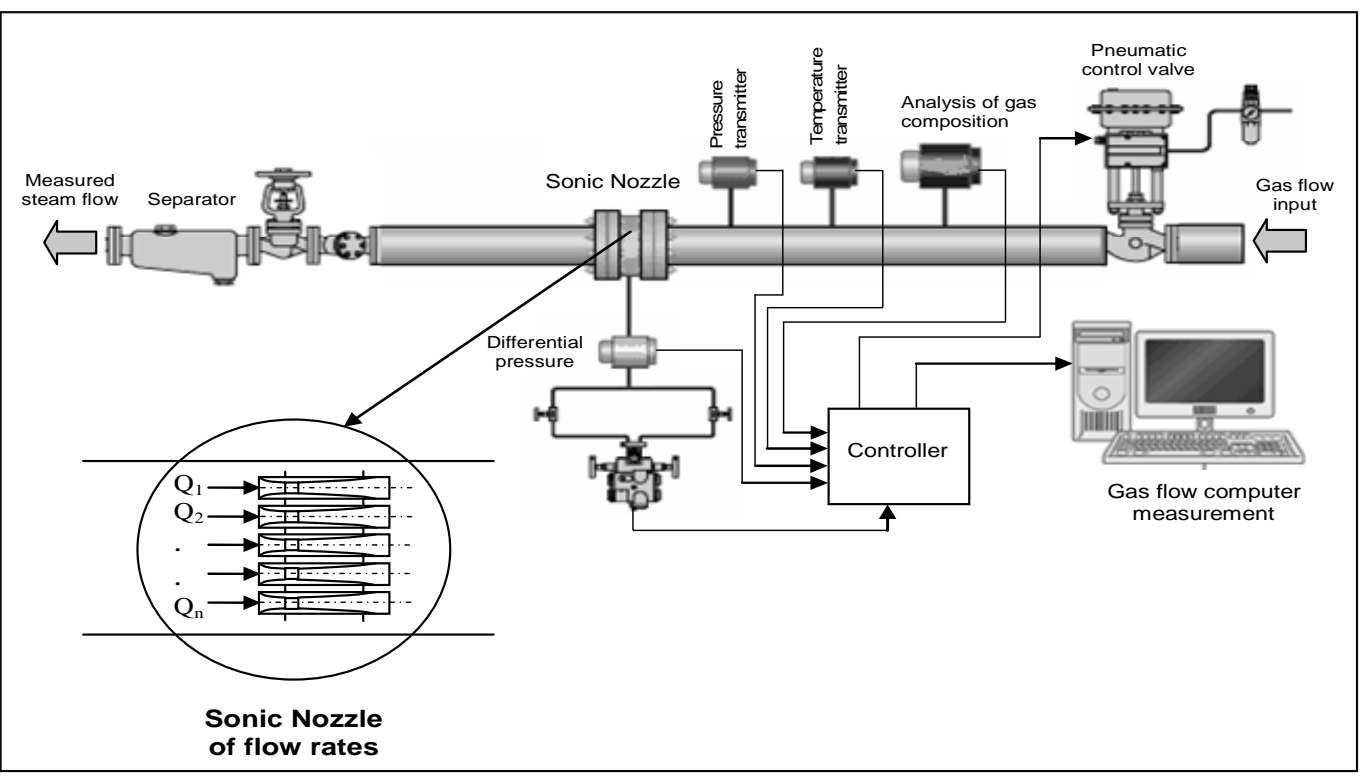

Figure 3. Gas flow measurement and control in gas pipeline system using intelligent sonic nozzle sensor

The flow computer provide the intelligence and the controls necessary to run the proving process, to calculate the correct sonic nozzle flow rates, the prover uses modern electronics and a sophisticated computer technology, shown in Figure 4, this flow computers can be applied when the measurement error due to actual operating conditions becomes large enough to be unacceptable in the application. The measurement error can be estimated by calculation using worst case operating conditions. installed on the network of pipelines of Sonatrach (compound of 14 pipelines and 13 gas pipelines and overall length of 14.495 $\mathrm{km}$ ), are mainly plates with opening (or diaphragm), venturi and turbines; Flowmeters with ultrasounds start to be installed since the beginning of the years 1990. The calculations on this page are for nozzles carrying a liquid as described in ISO 3500. The ISO equations are used in our calculations in this work. 


\subsection{Discharge coefficients}

For each type of nozzle, a graph of discharge coefficient function of $\mathrm{Re}_{\mathrm{D}}$ or $\mathrm{d} / \mathrm{D}$ is shown in figures 5, 6 and 7. Each graph is followed by the equation used by Simons in [24].

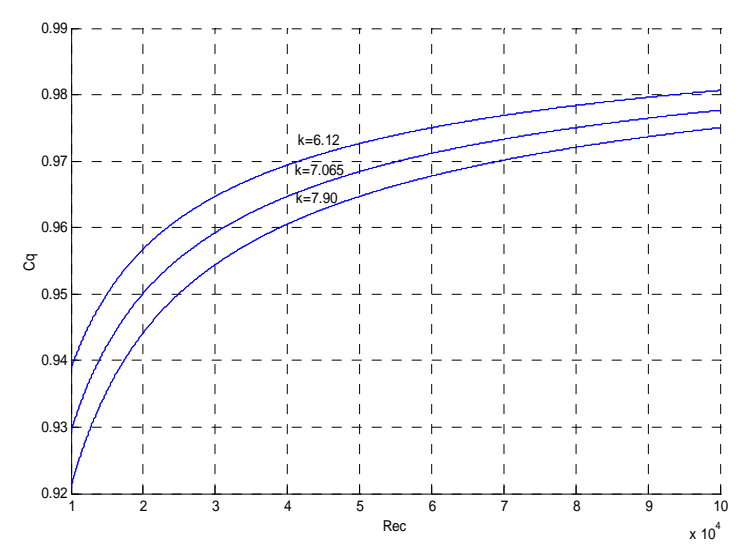

Figure 5. Nozzle discharge coefficient used by Simons in [24] With: $C_{c}=1-\frac{K}{\sqrt{\mathrm{Re}_{c}}}$ for $10^{4} \leq R e_{c} \leq 10^{5}$.and $\mathrm{K}=6,12 ; 7,065$ and 7,90

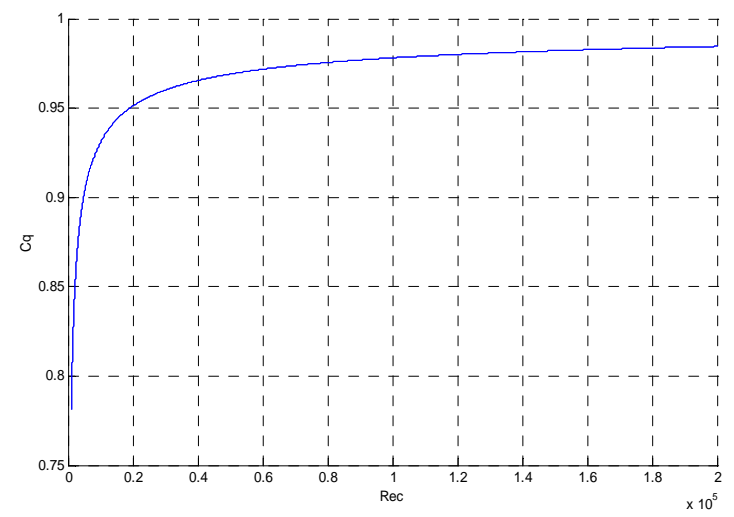

Figure 6. Nozzle discharge coefficient function fo Reynolds number With: $C_{q}=1-\frac{6,92}{\sqrt{\mathrm{Re}_{c}}}$ for $10^{3} \leq R e_{c} \leq 2.10^{5}$

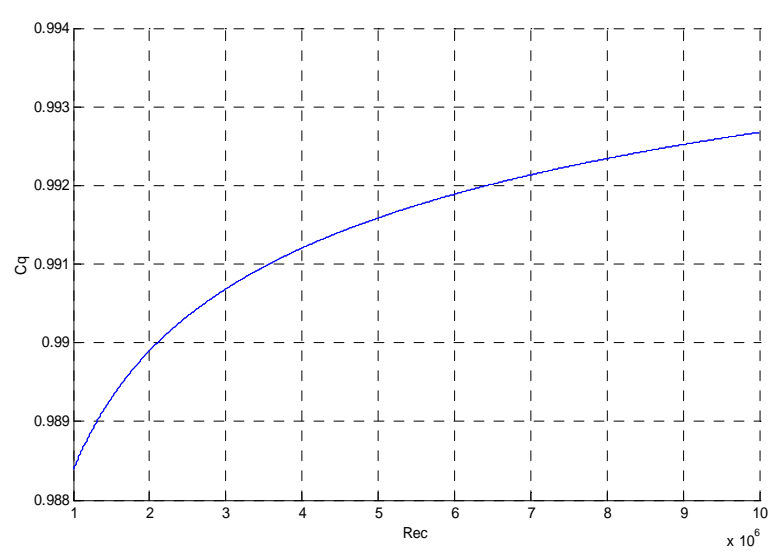

Figure 7. Venturi nozzle discharge coefficient With: $C_{q}=1-\frac{0,184}{\operatorname{Re}_{c}^{0.2}}$, for $10^{6} \leq \operatorname{Re}_{c} \leq 10^{7}$ 


\section{Results and Discussion}

The experimental test setup is shown schematically in figures 8.a, 8.b and 8.c, two flow venturi FVs are installed upstream of the chamber in gas pipeline. They are identified as FV01 and FV02. The objective of adding the third FV is to isolate the source of any observed variance in the test chamber of sonic nozzle in parallel montage. This is accomplished by comparing the results of any two FVs relative to the third. The Determining the variance contributed by the multiple FV chamber in parallel montage compared to that contributed by a single unit is of particular interest.

\subsection{Venturi nozzle test}

According to the assumption of isentropic flow, the sonic and subsonic elsewhere neck, leaving the continuity equation at the neck and out of the venturi nozzle, was obtained for the expression (14):

$$
\begin{aligned}
& W_{c r, s} \frac{1}{\gamma} \cdot\left(W_{c r, s} \frac{1}{\gamma}-W_{c r, s}\right)= \\
& \left(\frac{2}{\gamma+1}\right)^{\frac{2}{\gamma-1}} \cdot\left(\frac{\gamma-1}{\gamma+1}\right) \cdot\left(\frac{S_{c}}{S_{s}}\right)^{2}
\end{aligned}
$$

As the geometry of venturi nozzle we have adopted:

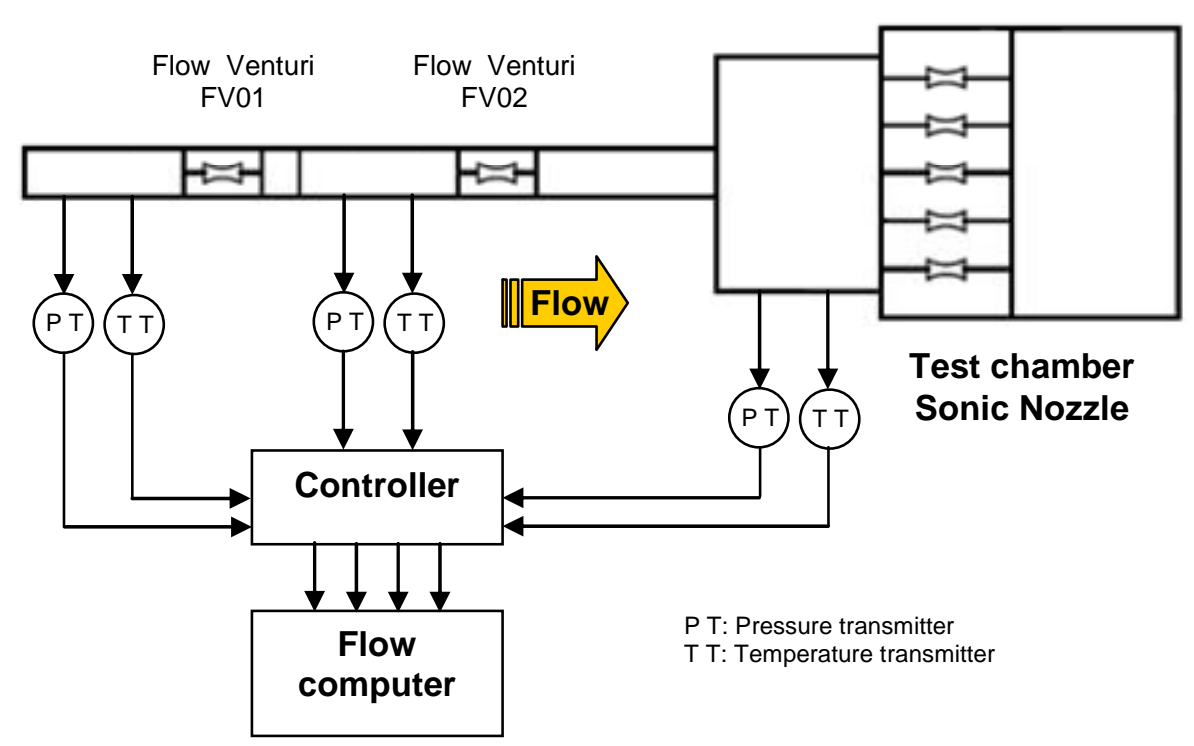

Figure 8.a. Experimental test

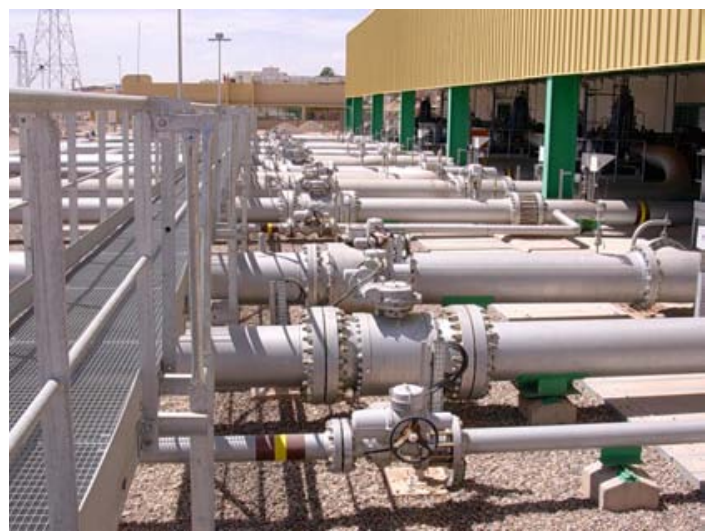

Figure 8.b. Experimental test

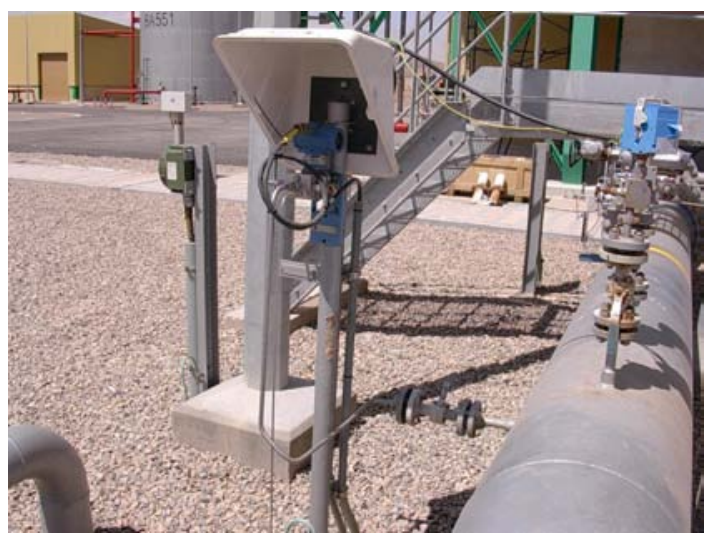

Figure 8.c. Experimental test 
$\frac{d s}{d c}=1+2\left(\frac{L_{t}}{d c}-2\right) \cdot \operatorname{Tg} \theta$ and $\theta=3^{\circ} 30^{\prime}$.

It takes time:

$\left.\frac{L_{t}}{d c}=2+\frac{\operatorname{Cotg} \theta}{2} \cdot \sqrt{\frac{\left(\frac{2}{\gamma+1}\right)^{\frac{2}{\gamma-1}}\left(\frac{\gamma-1}{\gamma+1}\right)}{W_{c r, s} \frac{1}{\gamma}\left(W_{c r, s} \frac{1}{\gamma}-W_{c r, s}\right)}}-1\right)$ (22)
By giving values to the report $\frac{L_{t}}{d c}$ and calculate the corresponding $\mathrm{W}_{\mathrm{cr}}$ report. The results obtained for the reports critical function of the angle of divergence are shown in Figure 9.

For the results obtained for the reports critical function of Lt / dc are shown in Figure 10.

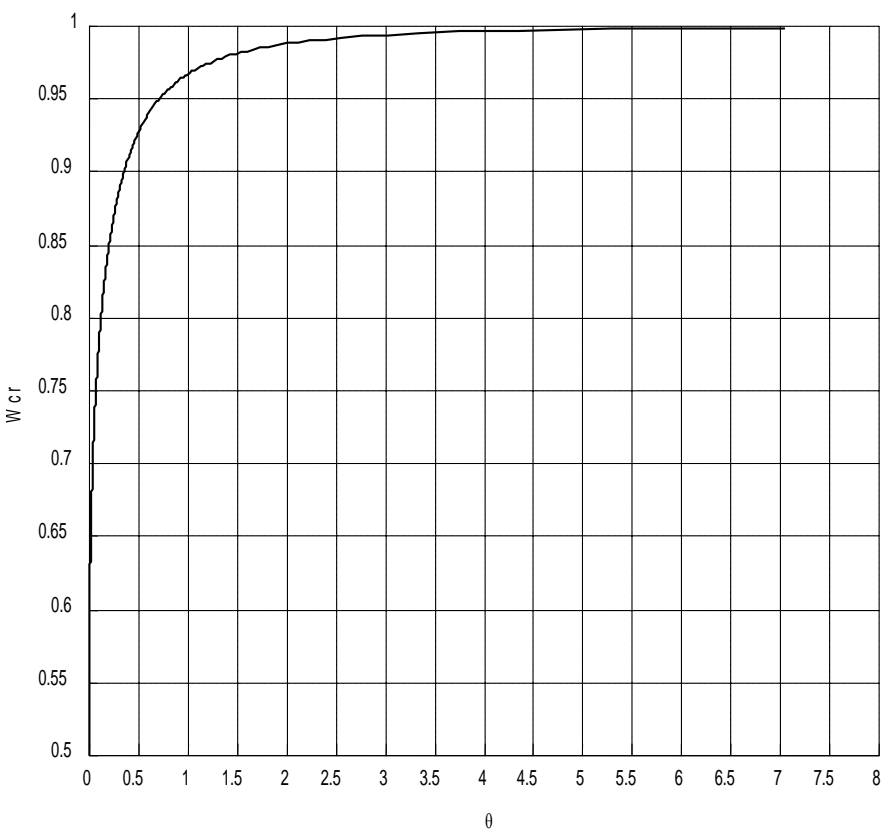

Figure 9. Reports critical function of the angle of divergence

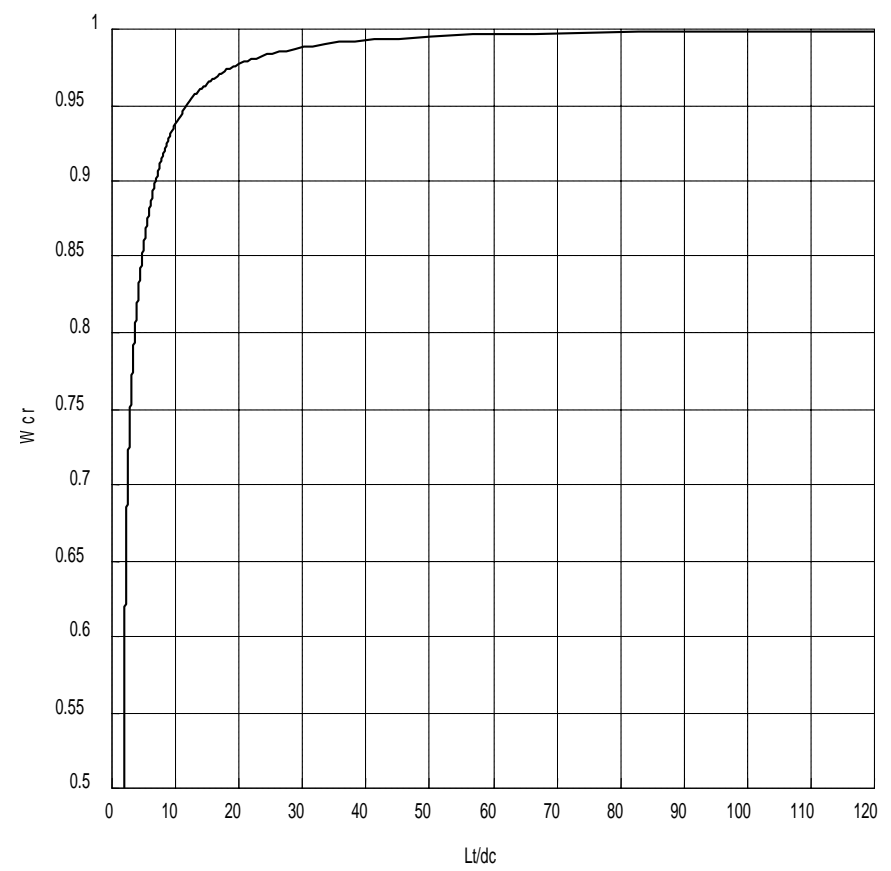

Figure 10. Reports critical function of Lt / dc 
Other tests results investigated in the examined gas pipeline system are presented in this section. The Influence of the compressibility factor on the rate flow, for the pressure and temperature, in the intelligent sonic nozzle sensor is shown in figures 11 and 12.

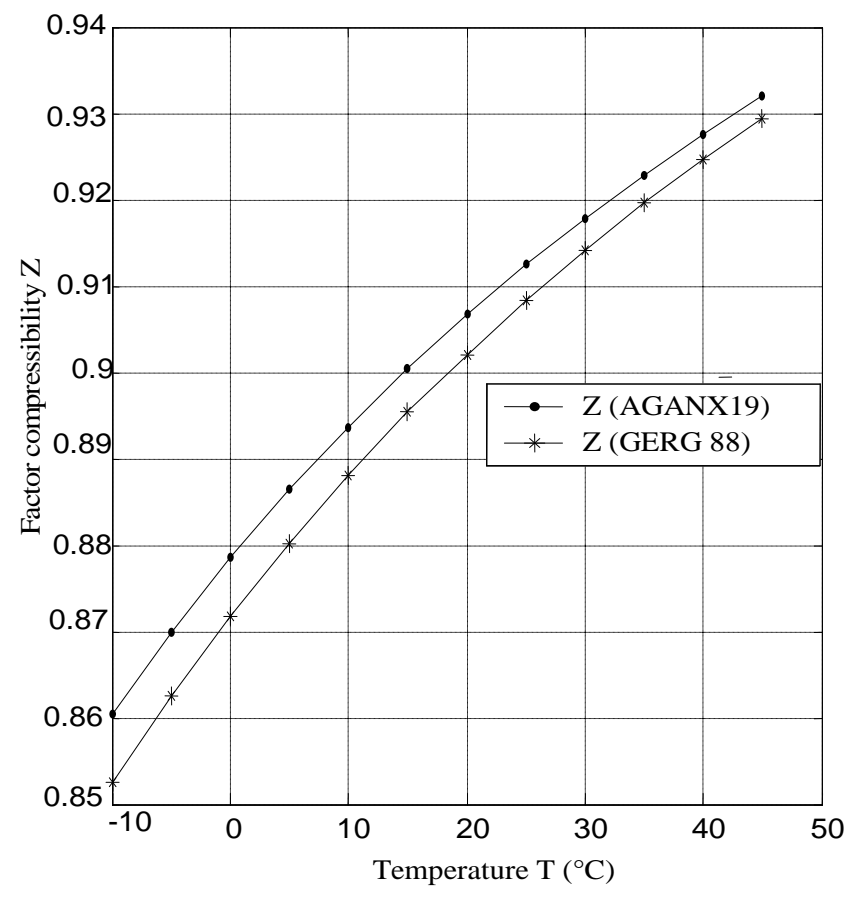

Figure 11. Influence of the compressibility factor on the rate flow for the temperature

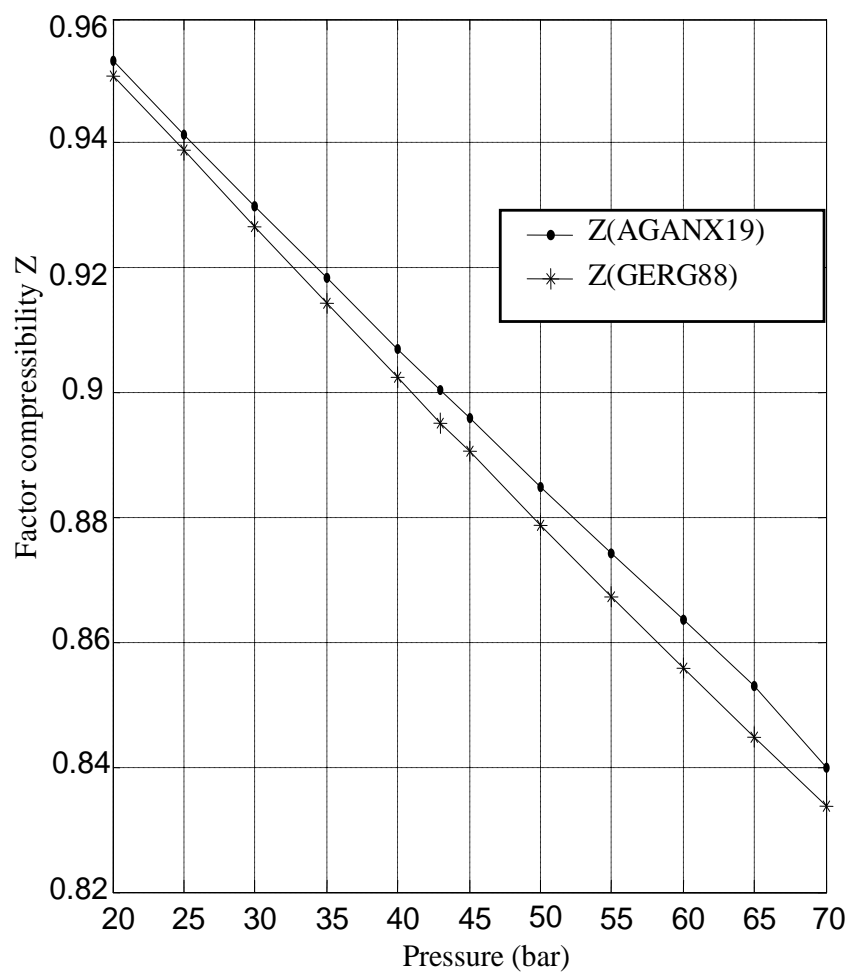

Figure 12. Influence of the compressibility factor on the rate flow for the pressure 
The tests results of the rate flow calculus according to ISO5167 with Z (AGANX19) and $\mathrm{Z}$ (GERG88) (tabled in Table 01) is shown in Figure 13. success of the system of measurement of the gas flow, the nature of the flow and the factors influencing this one. In this case, we

Table 1. Rate flow values according to ISO5167 with Ps $=43$ bars

\begin{tabular}{lll}
\hline \hline Temperature ${ }^{\circ} \mathrm{C}$ & $\mathrm{Q}\left(\mathrm{Z}(\right.$ AGANX19) $) \mathrm{m}^{3} / \mathrm{h}$ & $\mathrm{Q}(\mathrm{Z}($ GERG 88$)) \mathrm{m}^{3} / \mathrm{h}$ \\
\hline-10 & 198181.3 & 199099.6 \\
-5 & 195463.2 & 196094.6 \\
0 & 192517.1 & 193265.9 \\
5 & 189924.1 & 190595.1 \\
10 & 187469.2 & 188066.7 \\
15 & 185139.4 & 185667.3 \\
20 & 182923.2 & 183385.7 \\
25 & 180811.4 & 181211.8 \\
30 & 178795.9 & 179136.9 \\
35 & 176849.7 & 177153.3 \\
40 & 174987.5 & 175254.1 \\
45 & 173198.0 & 173433.5 \\
\hline \hline
\end{tabular}

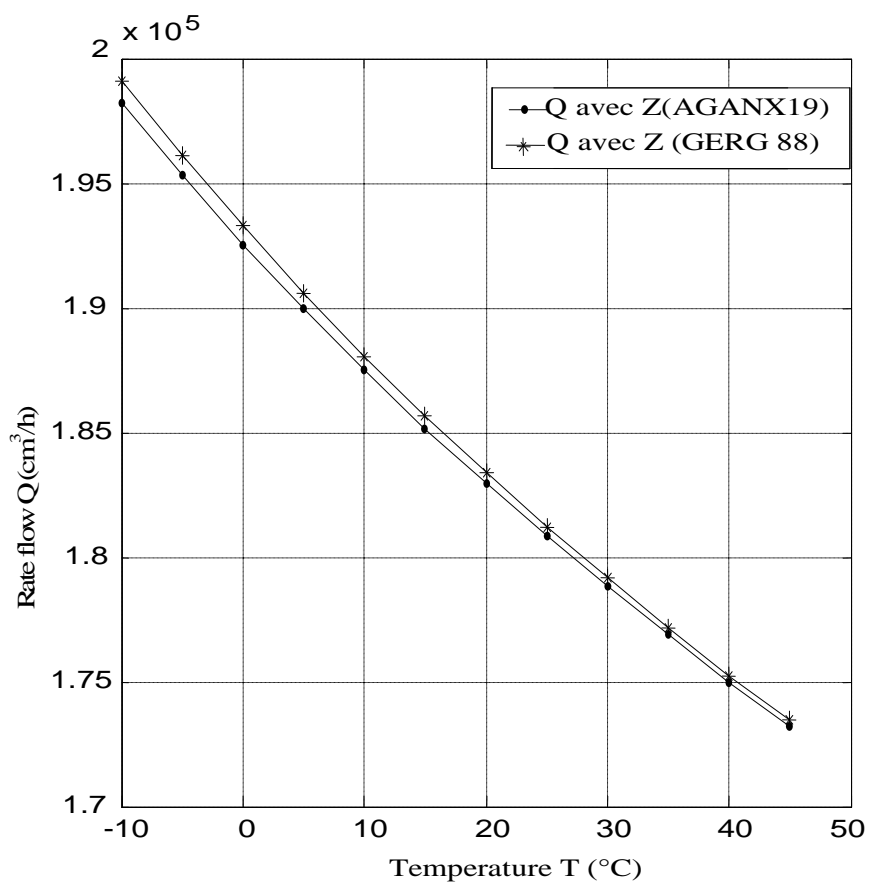

Figure 13. Response of the rate flow calculus according to ISO5167

\section{Conclusion}

In this work, we exposed by the means examples of the use of new methods and systems of measurement of the gas flow in a single unit of gas pipeline, we based ourselves on sonic nozzle sensor and their techniques of use, as well as compared with the various types of flowmeters. For the systems of the flowmeters of the industrial fluids, an essential problem conditions the showed that use of conduit of the tube of venturi with opening could be an alternative or at least an effective contribution to the problems encountered at the time of the phase of determination of the measurement of flow transported with a satisfactory precision is necessary. In this work, we showed that use of a sonic nozzle sensor, the great advantage of these nozzles is determining the flow measurements with great precision, which makes them indispensable as regulators and 
stabilizers of flow during the calibration of the other measuring means. The design parameters of the sonic nozzle were optimized by the used of a flow computer, to determine the mathematically correct of the raw flow measurement to account for realtime changes in operating pressure and temperature. With this method, this optimized design enables a constant flow rate control to be attained with a substantial reduction in the gas pipeline capacity requirement and cost.

\section{Nomenclature}

A: Coefficient of expansion,

a: Speed of sound and $\mathrm{C}_{\mathrm{p}}$ : Specific heat

$\mathrm{C}_{\mathrm{q}}$ :, Overall coefficient of flow

D: Diameter and $\mathrm{d}_{\mathrm{c}}$ : Diameter at collar

$\mathrm{F}_{\mathrm{h}}$ : Moisture humidity Factor

g: Acceleration of gravity

$\mathrm{K}$ :, Numerical constant

L: Length, $\mathrm{L}_{\mathrm{c}}$ : Cervical Length

M: Mach number

P: Pressure

$\mathrm{P}_{\mathrm{am}}$ : Stagnation pressure upstream of the Venturi nozzle

$\mathrm{P}_{\mathrm{c}}$ : , Static pressure at the neck

$\mathrm{P}_{\mathrm{d}}$ : Dynamic pressure

$\mathrm{P}_{\mathrm{v}}$ : Partial pressure of water vapour

$\mathrm{Q}$ : Mass Flow and $\mathrm{Q}_{\mathrm{th}}$ : Theoretical mass flow

$\mathrm{Q}_{\mathrm{r}}$ : Actual mass flow

Re:, Reynolds number

$\mathrm{Re}_{\mathrm{c}}$ : Reynolds number at neck

$\mathrm{r}_{\mathrm{ah}}$ : Constant of wet gas

$r_{a s}$ : Constant dry gas

S: Cross section

$\mathrm{S}_{\mathrm{av}}$ : Cross section at the exit of the Venturi nozzle

$\mathrm{S}_{\mathrm{c}}$ : Cross section neck

$\mathrm{T}$ :, Absolute temperature

$\mathrm{T}_{\mathrm{am}}$ : Absolute temperature upstream of the

Venturi nozzle

$\mathrm{T}_{\mathrm{c}}$ : Absolute temperature neck

$\mathrm{U}$ : Speed, $\mathrm{U}_{\mathrm{c}}$ : Speed neck

W: Critical ratio

$\mathrm{W}_{\mathrm{cr}, \mathrm{c}}$ : Report critical pressure to the neck and upper

$\mathrm{W}_{\mathrm{cr}, \mathrm{av}}$ :Report critical pressure downstream and upstream

$\rho$ : Density, $\rho_{\mathrm{a}}$ : Gas density, $\rho_{\mathrm{c}}$ : Density neck.

$\rho_{\mathrm{am}}$ : Density of the gas upstream

\section{REFERENCES}

1. AISSANI, S., E. MIKAELIAN, Operational characteristics for gas pipelines in Algeria from 1976 to $\mathbf{1 9 8 0 ,}$
Oil \& Gas Science and Technology, Revue of IFP, vol. 37(6), 1982, pp. 847-852.

2. BIGNELL, N., Using Small Sonic Nozzles as Secondary Flow Standards, Flow Measurement and Instrumentation, Elsevier, vol. 11(4), 2000, pp. 329-337.

3. BOUAM, A., R. KADI, S. AÏSSANI, Gas Turbine Performances Improvement Using Steam Injection in the Combustion Chamber under Sahara Conditions, Oil \& Gas Science and Technology, Revue of IFP, vol. 63(2), 2008, pp. 251-261.

4. CHOI, Y. M., K. A. PARK, J. T. PARK, H. M. CHOI, S. O. PARK, Interference Effects of Three Sonic Nozzles of Different Throat Diameters in the Same Meter Tube, Flow Measurement and Instrumentation, Elsevier, vol. 10(3), 1999, pp. 175-181.

5. CHUNG HU, C., W.-T. LIN, Performance Test of $\mathrm{KOH}$-etched Silicon Sonic Nozzles, Flow Measurement and Instrumentation, Elsevier, vol. 20(3), 2009, pp. 122-126.

6. FERROUK, M., S. AISSANI, F. D'AURIA, A. DELNEVO, A. BOUSBIA SALAH, Assessment of 12 CHF Prediction Methods, for an Axially Non-uniform Heat Flux Distribution, with the RELAP5 Computer Code, Nuclear Engineering and Design, Elsevier, vol. 238(10), 2008, pp. 2718-2725.

7. GUEMANA, M., S. AISSANI, A. BENNANI, The Compressibility Effect on the Counting Gas Method Choice, International Review of Mechanical Engineering, IREME, vol. 03(1), 2009, pp. 104-109.

8. HAFAIFA, A., K. LAROUSSI, F. LAAOUAD, Robust Fuzzy Fault Detection and Isolation Approach Applied to the Surge in Centrifugal Compressor Modeling and Control, Fuzzy Information and Engineering, Springer, vol. 02(1), 2010, pp. 49-73.

9. HAFAIFA, A., F. LAAOUAD, K. LAROUSSI, Fuzzy Approach Applied in Fault Detection and Isolation to the Compression System Control, Studies 
in Informatics and Control, SIC, vol. 19(1), 2010, pp. 17-26.

10. HAFAIFA, A., F. LAAOUAD, K. LAROUSSI, Fuzzy Logic Approach Applied to the Surge Detection and Isolation in Centrifugal Compressor, Automatic Control and Computer Sciences, Springer, vol. 44(1), 2010, pp. 53-59.

11. HAYAKAWA, M., Y. INA, Y. YOKOI, M. TAKAMOTO, S. NAKAO, Development of a Transfer Standard with Sonic Venturi Nozzles for Small Mass Flow Rates of Gases, Flow Measurement and Instrumentation, Elsevier, vol. 11(4), 2000, pp. 279-283.

12. ISO 9300:2005: Measurement of Gas Flow by Means of Critical Flow Venturi nozzles.

13. ISHIBASHI, M., E. Von LAVANTE, M. TAKAMOTO, Quasi Non-intrusive Measurement of Flow Velocity Field in a Critical Nozzle, Proceedings of ASME FEDSM’00, Boston, 2000.

14. KEGEL, T., C. BRITTON, R. CARON, Measurement Uncertainty Considerations when using an Array of Critical Flow Venturies, Proceedings of the $46^{\text {th }}$ International Instrumentation Symposium, Instrument Society of America, 2000.

15. M. LEBRUN, D. VASILIU and N. VASILIU, Numerical Simulation of the Fluid Control Systems by AMESim, Studies in Informatics and Control, SIC, vol. 18(2), 2009, pp. 111-118.

16. LIU, S., Q. CHEN, H.G. WANG, F. JIANG, I. ISMAIL, W.Q. YANG, Electrical Capacitance Tomography for Gas-Solids Flow Measurement for Circulating Fluidized Beds, Flow Measurement and Instrumentation, Elsevier, vol. 16(2-3), 2005, pp. 135-144.

17. MICKAN, B., R. KRAMER, E. Von LAVANTE, Determination of Discharge Coefficients of Sonic Nozzles with Low Uncertainty and Without Knowledge of Throat Diameter, Proceedings of the International Conference on Flow Measurement, FLOMEKO’2004, Guilin China, 2004.
18. LIM, J. M., B.-H. YOON, S. JANG, H.M. CHOI, K.-A. PARK, Step-down Procedure of Sonic Nozzle Calibration at Low Reynolds Numbers, Flow Measurement and Instrumentation, Elsevier, vol. 21(3), 2010, pp. 340-346.

19. NAKAO, S. I., Y. YOKOI, M. TAKAMOTO, Development of a Calibration Facility for Small Mass Flow Rates of Gas and the Uncertainty of a Sonic Venturi Transfer Standard, Flow Measurement and Instrumentation, Elsevier, vol. 07(2), 1996, pp. 77-83.

20. PARK, K. A., Y. M. CHOI, H. M. CHOI, T. S. CHA, B. H. YOON, The Evaluation of Critical Pressure Ratio of Sonic Nozzles at Low Reynolds Numbers, Flow Measurement and Instrumentation, Elsevier, vol. 12(1), 2001, pp. 37-41.

21. SZAKONYI, L., Investigation and Control of a Regional Steam Distribution Network under Two Phase Flow Conditions, Studies in Informatics and Control, SIC, vol. 18(2), 2009, pp. 119-126.

22. WRIGHT, P. H., The Application of Sonic (Critical Flow) Nozzles in the Gas Industry, Flow Measurement and Instrumentation, Elsevier, vol. 04(2), 1993, pp. 67-71.

23. ZHENG, Y., J. R. PUGH, D. MCGLINCHEY, R. O. ANSELL, Simulation and Experimental Study of Gas-to-Particle Heat Transfer for Noninvasive Mass Flow Measurement, Measurement, Elsevier, vol. 41(4), 2008, pp. 446-454.

24. SIMONS, F. S., Analytic Determination of the Discharge Coefficient of Flow Nozzles, NACA, TN 344, 1955. 